\title{
10 ANOS DA REVISTA MULTIFACE E O INCENTIVO À PESQUISA NA GRADUAÇÃO
}

Josiel Gomes Costa ${ }^{1}$; Eduardo Pascoal de Freitas ${ }^{2}$; Ivan Prates Sternick ${ }^{3}$; Ana Carolina de Lima $^{4}$; Giovanni Salvador Santos${ }^{5}$; Vitor Salomão Mourão; ${ }^{6}$ Cláudio Procópio Damasceno Filho $^{7}$

Como citar:

COSTA, J. G.; FREITAS, E. P.; STERNICK, I. P.; LIMA, A. C.; SANTOS, G. S.; MOURÃO, V. S.;

DAMASCENO FILHO, C. P. 10 anos da revista multiface e o incentivo à pesquisa na graduação. In: ABEC

MEETING, 1, 2017, Curitiba. Anais... Curitiba: Associação Brasileira de Editores Científicos, 2017. p. 14-20.

http://dx.doi.org/10.21452/abecmeeting.2017.003

Resumo: A revista Multiface é um periódico organizado por alunos de graduação da UFMG e que publica exclusivamente trabalhos produzidos por graduandos, nas áreas de Economia, Administração e Relações Econômicas Internacionais. Contando com 10 anos de existência e sendo uma revista disponibilizada no formato digital, a Multiface tem recebido trabalhos de alunos das mais diversas universidades do país. O processo de avaliação busca sempre produzir pareceres construtivos, os quais possam contribuir para a formação de novos pesquisadores desde a graduação. Além disso, a existência de uma revista editorada por alunos de graduação possibilita a formação de membros de comitês editoriais desde a graduação.

Palavras-chave: periódico discente, pesquisa, publicação.

Abstract: Multiface magazine is a journal organized by undergraduate students of UFMG and publishes exclusively works produced by undergraduates in the areas of Economics, Administration and International Economic Relations. With 10 years of history and being a magazine available in digital format, Multiface has received works from students of several universities of Brazil. The evaluation process always seeks to produce constructive opinions, which may contribute to the shaping of new researchers since undergraduate courses. In addition to that, the existence of a journal published by undergraduate students allows the shaping of members to editorial committees since this level of education.

Keywords: undergraduate journal, research, publication.

\section{INTRODUÇÃO}

Com o objetivo de estimular a produção científica a nível de graduação, a Revista Multiface surgiu em 2007, a partir de uma iniciativa de alunos bolsistas do Programa de Educação Tutorial (PET) da Faculdade de Ciências Econômicas (FACE) da Universidade Federal de Minas Gerais (UFMG). Desde a época de publicação da primeira edição, a revista contou com o apoio de diversos órgãos da universidade, tais como o Centro de Desenvolvimento e Planejamento Regional de Minas Gerais (CEDEPLAR) e a Fundação Instituto de Pesquisas Econômicas, Administrativas e Contábeis de Minas Gerais (IPEAD), além da UFMG Consultoria Júnior e do Diretório Acadêmico (DA) da FACE. Esse apoio foi primordial para que os nove bolsistas dos cursos de Administração, Ciências Econômicas e Ciências Contábeis executassem as tarefas editoriais e conseguissem viabilizar a audaciosa impressão de 1.000 exemplares logo na primeira edição da revista. Com o objetivo de se tornar referência nacional no que diz respeito a publicações periódicas exclusivas para estudantes de graduação, a Revista Multiface completou 10 anos de existência em 2017. 
COSTA, J. G.; FREITAS, E. P.; STEMICK, I. P.; LIMA, A. C.; SANTOS, G. S.; MOURÃO, V. S.; DAMASCENO FILHO, C. P.

"10 anos da revista multiface e o incentivo à pesquisa na graduação"

Nesse sentido, o presente trabalho tem como objetivo apresentar o periódico e suas características que o tornam um espaço de incentivo à pesquisa na graduação. No decorrer do trabalho, retoma-se brevemente a trajetória da revista e descreve-se sua estrutura e seu funcionamento que permitem a publicação contínua de qualidade. Também são apresentadas informações relevantes acerca da revista e de suas publicações passadas. Por fim, faz-se uma reflexão sobre os desafios e perspectivas da publicação, tendo em vista seus 10 anos e seus objetivos para o futuro.

\section{A ESTRUTURA DA REVISTA}

Após o lançamento de nove edições, os sucessivos contingenciamentos de recursos fizeram com que os principais financiadores da revista em formato impresso retirassem a quantia que era repassada à Multiface. Por conta disso, a revista ficou inativa por dois anos, sendo retomada em 2014, novamente pelos bolsistas, mas dessa vez com o nome de Revista Multiface Online, disponível apenas no formato virtual, como o novo nome sugere. A revista está hospedada no endereço eletrônico revistas.face.ufmg.br/multiface e utiliza a plataforma Open Journal System (OJS), também conhecida no Brasil como Sistema Eletrônico de Editoração de Revistas (SEER), para gerenciamento e suporte à publicação online. A quase totalidade dos principais periódicos científicos da área utilizam a mesma plataforma.

A revista continua recebendo exclusivamente trabalhos de alunos de graduação, nas áreas de Administração, Economia e Relações Econômicas Internacionais. Além de artigos, são publicadas resenhas, cases e textos introdutórios nessas áreas. Os artigos submetidos devem ser inéditos e resultantes de pesquisa científica original ou de trabalhos feitos para conclusão de curso. Além de artigos das áreas já citadas anteriormente, há uma seção para publicação de artigos livres, que são aqueles que não se enquadram nessas áreas.

As resenhas publicadas possuem o objetivo de apresentar um texto, livro, filme ou documentário, fornecendo uma ideia do assunto principal da obra e uma análise crítica a partir de outras referências. Os textos introdutórios, por sua vez, objetivam introduzir um tema ou debate relevante nas áreas de Economia ou Administração, de forma menos densa. Essa seção é voltada para os autores que estão começando sua trajetória acadêmica e permite o contato com a publicação sem a complexidade de um artigo. Os textos introdutórios em geral apresentam novas áreas de pesquisa e podem guiar a elaboração de um trabalho futuro.

Os cases publicados são estudos de caso a respeito de uma empresa, de um projeto ou mesmo de um grupo, mostrando a aplicação prática de teorias ensinadas na sala de aula. Além disso, a revista conta com uma seção de entrevistas (relatos de profissionais que possam 
COSTA, J. G.; FREITAS, E. P.; STEMICK, I. P.; LIMA, A. C.; SANTOS, G. S.; MOURÃO, V. S.;

"10 anos da revista multiface e o incentivo à pesquisa na graduação"

contribuir para uma nova visão dos graduandos sobre as suas áreas de atuação), bem como com um espaço do DA, no qual é apresentada uma análise de uma questão que influencia a comunidade universitária, sob a perspectiva desse importante órgão de mobilização estudantil.

\section{O PROCESSO EDITORIAL}

Acumulando as tarefas editoriais de divulgação, de diagramação, de orçamento e todas as demais tarefas necessárias à publicação da revista, atualmente o comitê editorial da revista Multiface é composto por representantes dos PETs dos cursos de Administração e Ciências Econômicas e por bolsistas do Sistema de Bolsas do curso de Relações Econômicas Internacionais, todos da UFMG. Sendo diretamente responsáveis pelo desenvolvimento da revista, os membros do comitê editorial são alterados quando deixam de fazer parte dos programas citados.

O processo de avaliação dos artigos é executado no sistema blind review, sendo entregues a pareceristas anônimos do conselho editorial ou para especialistas ad hoc anônimos para apreciação e emissão de parecer. O fluxo do processo de avaliação segue o processo utilizado nos principais periódicos científicos e está resumido na figura 1. 
COSTA, J. G.; FREITAS, E. P.; STEMICK, I. P.; LIMA, A. C.; SANTOS, G. S.; MOURÃO, V. S.;

DAMASCENO FILHO, C. P.

"10 anos da revista multiface e o incentivo à pesquisa na graduação"

Figura 1 - Fluxograma do processo de avaliação dos trabalhos submetidos à revista.

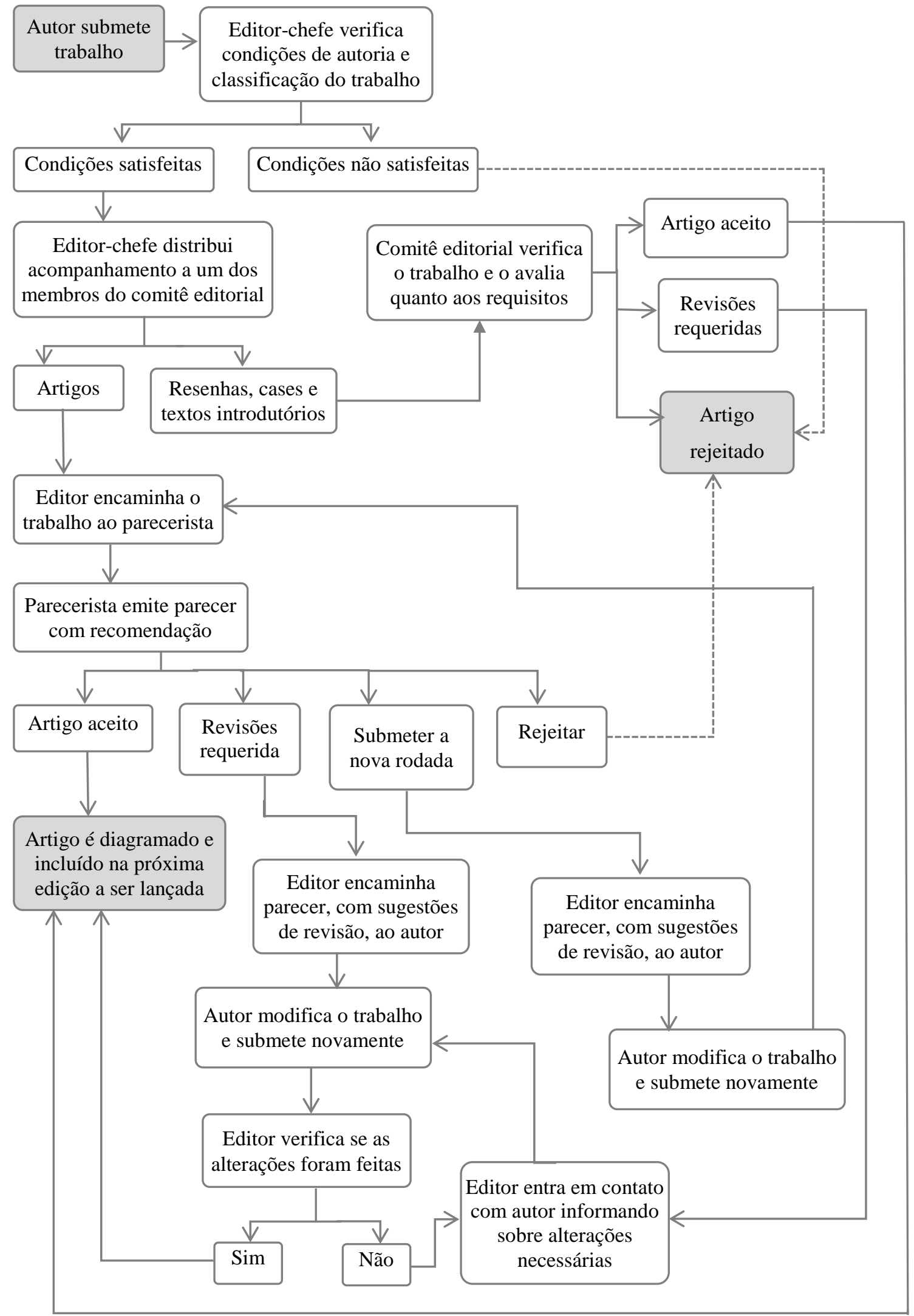

Fonte: elaborado pelos autores.

No fluxograma é possível notar que as resenhas, cases e textos introdutórios são avaliados pelo próprio comitê editorial. Os membros do comitê editorial avaliam as resenhas 
COSTA, J. G.; FREITAS, E. P.; STEMICK, I. P.; LIMA, A. C.; SANTOS, G. S.; MOURÃO, V. S.; DAMASCENO FILHO, C. P.

"10 anos da revista multiface e o incentivo à pesquisa na graduação"

no que tange à capacidade do texto de difundir o conhecimento da obra no debate acadêmico e cultural, enquanto os textos introdutórios são avaliados pela clareza de exposição do tema, verificando também se há apoio adequado na literatura consolidada da área. No que concerne aos cases, sua avaliação tem em vista a relevância do projeto apresentado, assim como das alternativas de solução ou condução do projeto apresentadas. Os artigos, da área livre ou não, por sua vez, são apreciados em termos gerais nos seguintes pontos: originalidade, atualidade e relevância do artigo; articulação de ideias e qualidade de escrita e adequação às normas de publicação da revista. Também vale ressaltar que os pareceristas são instruídos a fornecer avaliações construtivas para a formação do aluno, identificando os pontos fortes dos trabalhos e recomendando novas leituras que possam ajudar a melhorá-lo.

\section{ESTATÍSTICAS E INFORMAÇÕES}

A revista Multiface foi incorporada ao Portal de Periódicos da UFMG e, mais recentemente, ao Portal Periódicos de Minas, que é uma iniciativa da FAPEMIG (Fundação de Amparo à Pesquisa do Estado de Minas Gerais) para disponibilizar acesso a quase 400 revistas científicas sediadas no Estado. Além disso, ela se encontra indexada em quatro grandes bases bibliográficas: Sistema Regional de Información en Línea para Revistas Científicas de América Latina, el Caribe, España y Portugal (Latindex), Directory of Open Access Journals (DOAJ), Scientific Indexing Services (SIS) e Google Scholar.

O periódico demonstra já ganhar capilaridade no que diz respeito a outras universidades do Brasil, e se espera alcançar outras universidades pelo mundo. Desde a primeira edição, a revista Multiface tem recebido trabalhos de universidades como USP, PUC-Rio, PUC-SP, UFMA, UFOP, UFPR, UFRGS, UFU e UFC, além de ter recebido uma submissão do Instituto Superior Politécnico de Viana do Castelo, de Portugal. Além disso, o número de submissões anuais e a quantidade de usuários cadastrados no site da revista cresceram desde a implantação do formato online, conforme se verifica no gráfico 1 abaixo: 
COSTA, J. G.; FREITAS, E. P.; STEMICK, I. P.; LIMA, A. C.; SANTOS, G. S.; MOURÃO, V. S.; DAMASCENO FILHO, C. P.

"10 anos da revista multiface e o incentivo à pesquisa na graduação"

Gráfico 1 - Total de submissões recebidas por ano e total de usuários cadastrados no site da revista.

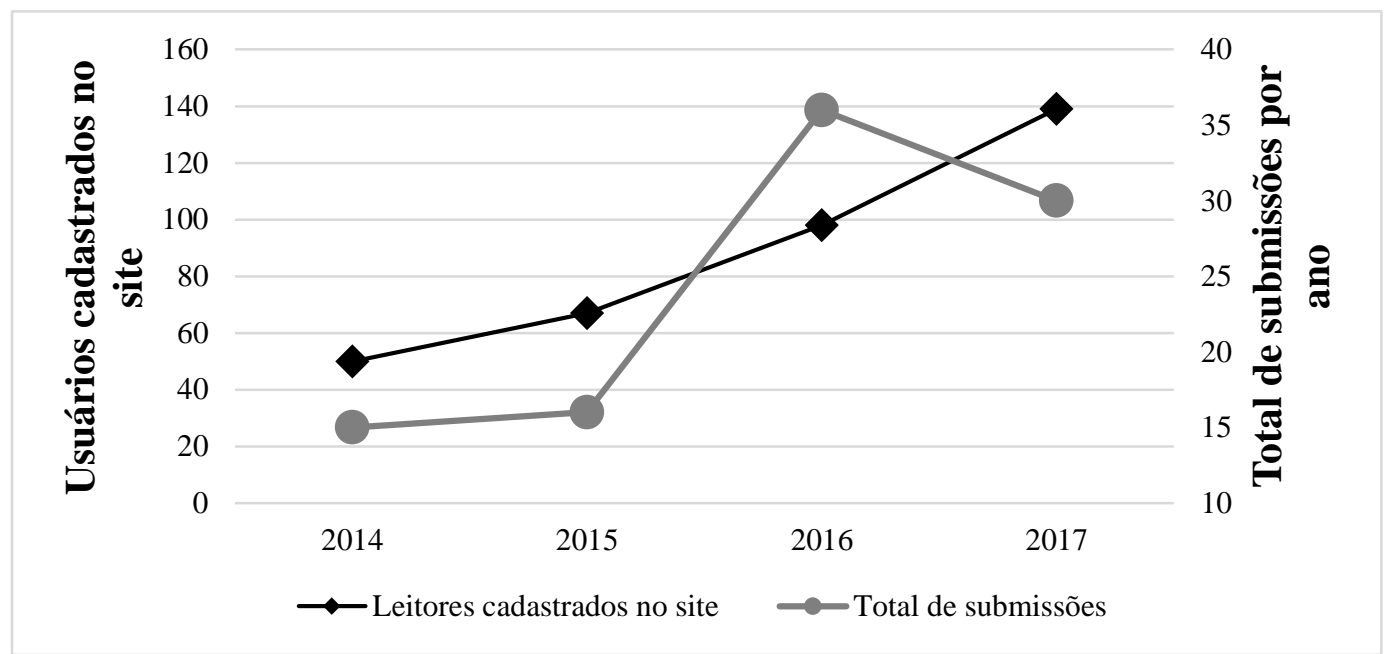

Fonte: elaboração própria a partir de dados da Plataforma OJS.

Relatórios retirados do sistema OJS apontam um tempo médio de avaliação de 27,41 dias entre a submissão e a conclusão de uma etapa de avaliação (seja a aceitação do artigo ou emissão do parecer pelo membro do conselho editorial). Os textos mais acessados na versão online da revista são da área de Economia, conforme é possível verificar no gráfico 2:

Gráfico 2 - Textos mais acessados na versão online da revista Multiface.

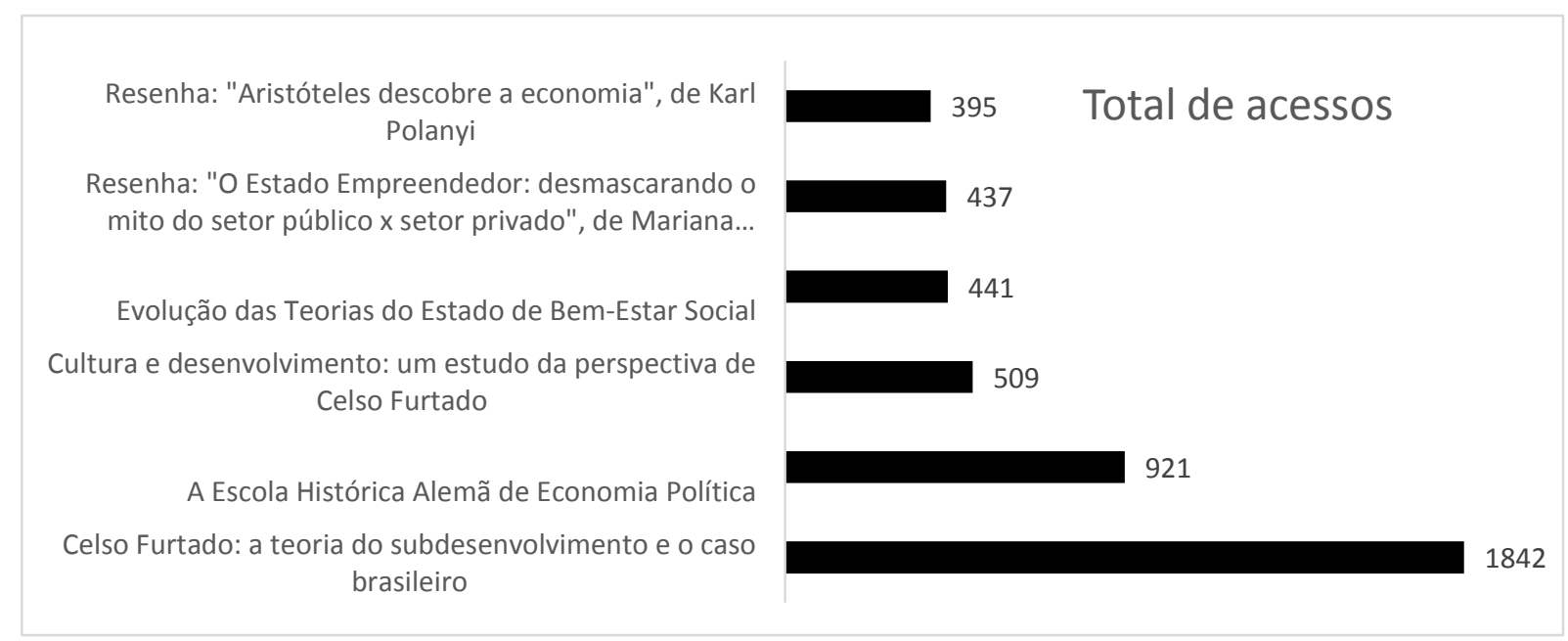

Fonte: elaborado pelos autores.

\section{DESAFIOS E PERSPECTIVAS}

O contingenciamento de recursos pelo qual tem passado a universidade pública se reflete também na área de divulgação da produção acadêmica e se constitui num desafio com o qual a publicação se depara. Além da impossibilidade de se existir uma versão impressa da revista, as limitações orçamentárias impostas à revista Multiface obrigam os membros do comitê editorial a utilizar ferramentas de detecção de plágio e diagramação gratuitas (os quais, apesar de servirem ao propósito principal, não oferecem as mesmas ferramentas de seus equivalentes pagos). Ademais, o armazenamento dos arquivos com as versões finais de todas as edições da revista é feito em servidores web que possuem limites de armazenamento que em breve serão atingidos.

Por outro lado, a oportunidade de participar de uma publicação científica durante a graduação se coloca como um importante meio de formação dos membros do comitê editorial. 
COSTA, J. G.; FREITAS, E. P.; STEMICK, I. P.; LIMA, A. C.; SANTOS, G. S.; MOURÃO, V. S.;

DAMASCENO FILHO, C. P.

"10 anos da revista multiface e o incentivo à pesquisa na graduação"

Isso porque a tarefa de organizar e coordenar um periódico em geral não faz parte dos currículos de pós-graduação e não é estimulada antes de se assumir esse tipo de tarefa. Como um periódico discente, a revista Multiface favorece este tipo de capacitação.

Conforme exposto anteriormente, a revista Multiface se propõe a ser, primordialmente, um espaço para a formação de pesquisadores e busca oferecer ao estudante de graduação uma avaliação construtiva de seu trabalho. Isso representa uma ação de incentivo à pesquisa na graduação, bem como estimula a formação de futuros pesquisadores, os quais possuirão visão crítica diante do próprio trabalho e estarão dispostos a aprimorá-lo a partir de comentários de seus pares. Ao longo dos seus 10 anos, a revista cumpriu com sucesso esse propósito, e para os próximos anos, continua comprometida com a divulgação científica de alta qualidade advinda dos graduandos. 